\title{
Age-related changes in kinematics of the knee joint during deep squat
}

\author{
Shingo Fukagawa ${ }^{\mathrm{a}, \mathrm{e}}$, Alberto Leardini ${ }^{\mathrm{b}}$, Barbara Callewaert ${ }^{\mathrm{c}}$, Pius D. Wong ${ }^{\mathrm{d}}$ Luc Labey $^{\mathrm{d}}$, \\ Kaat Desloovere $^{\mathrm{c}}$, Shuichi Matsuda ${ }^{\mathrm{e}}$, Johan Bellemans ${ }^{\mathrm{a}}$ \\ ${ }^{a}$ Department of Orthopaedics, University Hospitals Leuven (campus Pellenberg), Katholieke \\ Universiteit Leuven, Weligerveld 1, 3212 Pellenberg, Belgium \\ ${ }^{\mathrm{b}}$ Movement Analysis Laboratory, Istituto Orthopedico Rizzoli, Italy \\ ${ }^{\mathrm{c}}$ Clinical Motion Analysis Laboratory, University Hospitals Leuven (campus Pellenberg), \\ Katholieke Universiteit Leuven, Belgium \\ ${ }^{\mathrm{d}}$ European Centre for Knee Research, Smith \& Nephew, Belgium \\ ${ }^{\mathrm{e}}$ Department of Orthopaedics, Kyushu University, Japan
}

\begin{abstract}
Researchers frequently use the deep knee squat as a motor task in order to evaluate the kinematic performance after total knee arthroplasty. Many authors reported about the kinematics of a normal squatting motion, however, little is known on what the influence of aging is. Twenty-two healthy volunteers in various age groups (range 21-75 years) performed a deep knee squat activity while undergoing motion analysis using an optical tracking system. The influence of aging was evaluated with respect to kinematics of the trunk, hip, knee and ankle joints. Older subjects required significantly more time to perform a deep squat, especially during the descending phase. They also had more knee abduction and delayed peak knee flexion. Older subjects were slower in descend than ascend during the squat. Although older subjects had a trend towards less maximal flexion and less internal rotation of the knee compared to younger subjects, this difference was not significant. Older subjects also showed a trend towards more forward leaning of the trunk, resulting in increased hip flexion and anterior thoracic tilt.
\end{abstract}

This study confirmed that some aspects of squat kinematics vary significantly with age, and that the basic methodology employed here can successfully detect these age-related trends. Older subjects had more abduction of the knee joint, and this may indicate the load distribution of the medial and lateral condyles could be different amongst ages. Age-matched 
control data are therefore required whenever the performance of an implant is evaluated during a deep knee squat.

\section{Keywords}

3D knee kinematics; Squat; Age-related changes 


\section{Introduction}

Squat is a motor task that requires wide range of motion of the knee joint under loaded condition. Knee surgeons therefore use the deep knee squat frequently as a method to evaluate knee function and knee kinematics after surgery. The way on how the operated knee performs in comparison to what is known for the normal knee joint is frequently used to quantify the result and eventually improve the design or surgical technique of the knee prosthesis. Numerous studies performed in patients who had total knee arthroplasty (TKA) have shown abnormal kinematic patterns as compared to the normal human knee [1], [2], [3], [4], [5] and [6]. Based upon these studies, newer designs are being developed continuously in order to restore the kinematics of the normal knees in a better way than previous designs [7]. Obviously, it is therefore crucial to know accurately how normal knee kinematics occur as the reference. Several authors have reported on the kinematics of the knee during a deep knee squat [8], [9] and [10]. However, to our knowledge, the influence of aging has not been evaluated well before on full three dimensional analysis including axial and coronal planes. Previous studies have indeed always used young subject as a control group in their evaluation of the knee squat [11] and [12].

Nevertheless, it is well known that aging has an important effect on knee kinematics during normal gait, so it is logical to assume that this is also true for other activities such as a deep squat. Older adults are reported to tend to walk slower and with shorter strides when compared to younger subjects [13], [14], [15], [16] and [17]. This is generally considered compensatory to the loss of motor function that occurs with aging [18] and [19]. The way how a certain activity is performed is a reflection of how the subject attempts to maximize comfort and endurance, and represents the best compromise between parsimony in energy utilization and safety. Older adults walk differently than younger subjects in order to increase stability and avoid falls, or to reduce the energetic cost of mobility. Therefore it is commonly believed that when studying joint kinematics during walking, this should be in comparison to an agematched control group to account for the variance with age [17].

Besides gait, squatting is the second most frequently studied motor task for evaluating knee function. The reason is that during squatting the patient performs an active and loaded deep flexion of both knees, which allows the surgeon to study the kinematics of the knee during almost full range of motion under active and loaded condition, with both eccentric and 
concentric quadriceps contraction. Several authors have reported on the effect of osteoarthritis or ACL-deficiency on the kinematics during squatting [20], [21], [22] and [23]. In contrast to gait however, the effect of aging has not been thoroughly investigated for squatting.

In case differences would exist between older and younger subjects in how they perform a deep knee squat, age-matched control data would be required as the standard for adequate comparison and evaluation of certain interventions such as TKA. The present study therefore intends to quantify how squat kinematics vary with increasing age. To describe these effects as detailed as possible we investigated an exhaustive list of kinematic parameters. It was thereby hypothesized that older subjects would show reduced knee range of motion in the three anatomical planes.

\section{Methods}

Twenty-two volunteers without musculoskeletal pathology were recruited for the study and gave their informed consent to participate. The study was approved by the ethical commission of University Hospitals Leuven in Belgium. The study group consisted of 14 males and eight females, with a mean age of 46.2 years (SD 21.4, range 21-76), and an average body mass index of 23.4 (SD 4.6, range 17.7-30.8). No subjects reported any condition that could affect their functional performance, except for one subject who had been treated one year previously for a right Achilles tendon rupture. His gait patterns demonstrated no evident effects on his knee motions.

\section{Kinematic analysis}

Each subject underwent one motion analysis session by a well-trained physical therapist, using a 14-camera standard infrared tracking system, which determined the 3D trajectories of 55 passive retro-reflective spherical markers (14 $\mathrm{mm}$ diameter) fixed onto the skin over anatomical landmarks of the lower limbs and trunk (Plug-in-Gait [24] with Knee Alignment Device [25], Vicon, Oxford, UK). In each session, subjects were asked to perform three repeated trials of a deep squat. For each squat, they were instructed to squat down as deep as possible and rise back up. No support from the upper limbs was allowed, such as gripping the thighs with the hands. Other aspects of the squat, such as speed and posture, were at the subjects' discretion.

\section{Data analysis}


Dynamic three-dimensional joint kinematics were calculated with Euler angles, then timenormalized over a $0-100 \%$ squat cycle. Start and end times of the cycle were defined at instances of maximal knee extension, from standing position to standing position. The resulting data were analyzed with automated procedures (Matlab, Mathworks, Natick, MA, USA) in order to extract several descriptive parameters of the kinematic curves, including timing measures and extreme values. These parameters were chosen for analysis as they were hypothesized to possibly vary with age. Standard repeatability indices were calculated specifically for the knee kinematic curves. Repeatability relative to the range of motion was measured with the coefficient of multiple correlation (CMC), while absolute repeatability was measured in degrees with the root-mean-squared error (RMS) of the curves [26].

The parameters measured for each subject were: age, body mass, height, and body-mass index (BMI); CMC, RMS, maximum, minimum, and excursion values of the knee rotations in the three anatomical planes during the squat; abduction-adduction and internal-external rotation angles of the hip and ankle at the start of the squat; time to complete the squat cycle; and percent of the squat cycle (\%cyc) at the instant of deepest flexion.

\section{Statistical analysis}

The correlations between age and each of these resulting motion parameters were calculated (Minitab, State College, PA, USA). Correlations were compared to the null hypothesis of zero correlation, with significance threshold set at $\mathrm{p}<0.05$.

\section{Results}

Subject characteristics are summarized in Table 1. No significant correlations were found for age versus height, weight, BMI, or kinematic consistency indices (Fig. 1) (p>0.10), demonstrating an even distribution of subject characteristics across the age range. However, age showed significant positive correlations with squat time $(\mathrm{R}=0.636, \mathrm{p}=0.001)$ and \%cycle at maximum knee flexion $(\mathrm{R}=0.488, \mathrm{p}=0.021)$ (Fig. 2). Squat time increased by $0.0581 \mathrm{~s}$ per year older, and \%cycle at deepest flexion increased by $0.311 \%$ per year older. Significant negative correlations were found for age versus minimum $(R=-0.586, p=0.004)$ and maximum $(\mathrm{R}=-0.559, \mathrm{p}=0.007)$ abduction-adduction angles in the knee joint, with older subjects showing more abduction. Maximum and minimum abduction-adduction angles decreased by $0.167^{\circ}$ and $0.276^{\circ}$ per year older, respectively. All the remaining parameters were not significantly correlated with age (Table 2 ). 

Table 1. Subject group characteristics.

\begin{tabular}{|c|c|c|c|c|c|}
\hline Subjects & $n$ Meı & Women & Mean & SD & Min Max \\
\hline \multirow{2}{*}{ All } & 2214 & 8 & Age 46.2 & 21.4 & 21.875 .4 \\
\hline & & & BMI 23.4 & 4.6 & 17.730 .8 \\
\hline \multirow{2}{*}{ Older $(>45$ years $)$} & 127 & 5 & Age 58.3 & 9.4 & 45.475 .4 \\
\hline & & & BMI 24.6 & 3.5 & 17.730 .8 \\
\hline \multirow{2}{*}{ Younger $(<45$ years $)$} & 107 & 3 & Age 31.7 & 9.8 & 21.844 .3 \\
\hline & & & BMI 22.1 & 2.7 & 18.627 .3 \\
\hline
\end{tabular}

Characteristics of analyzed subjects, including two age groups: subjects older and younger than 45 years. 


\section{Repeatability indices of knee kinematics curves, versus subject age}

$\underline{\text { CMC }}$
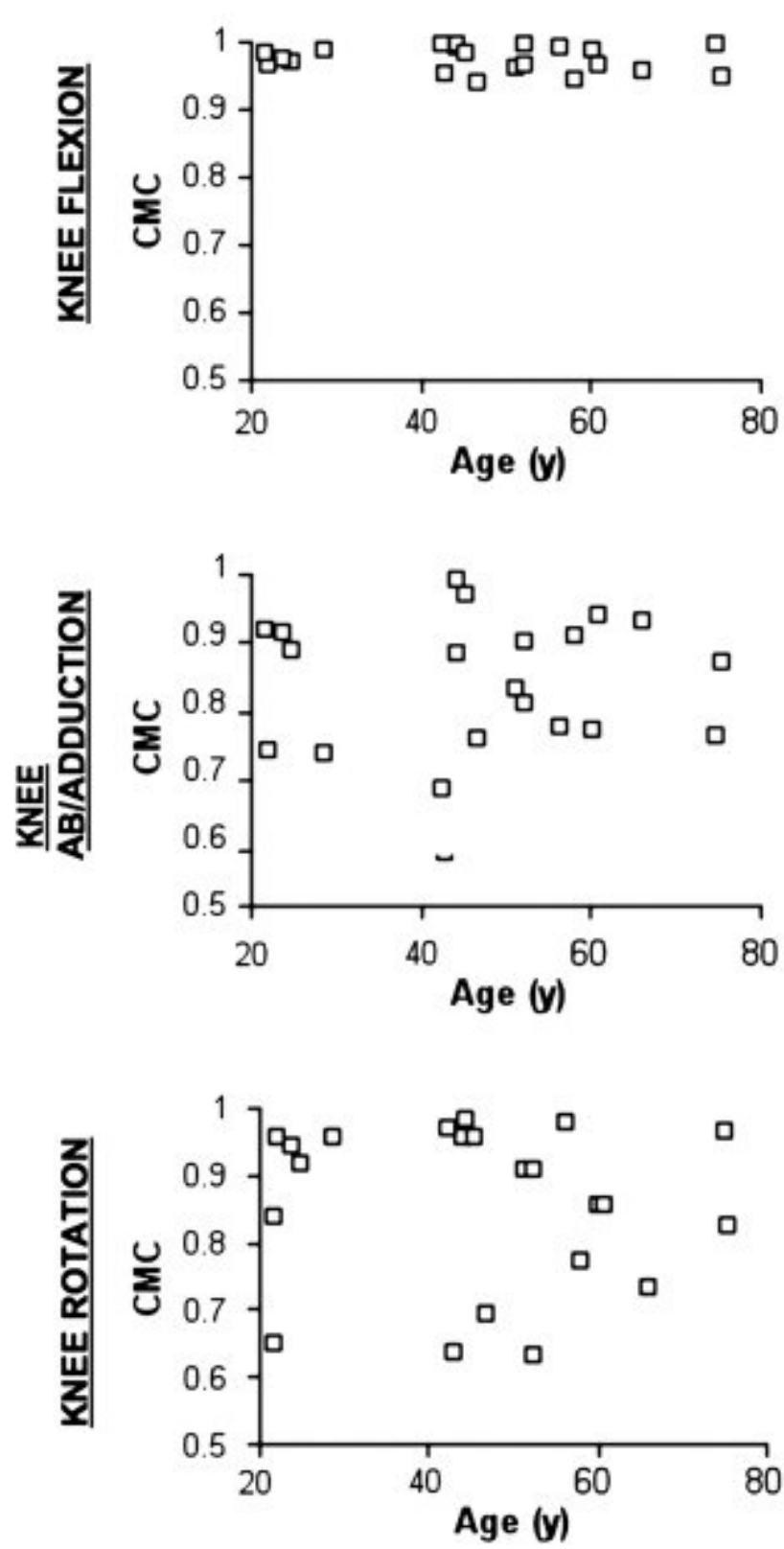

RMS
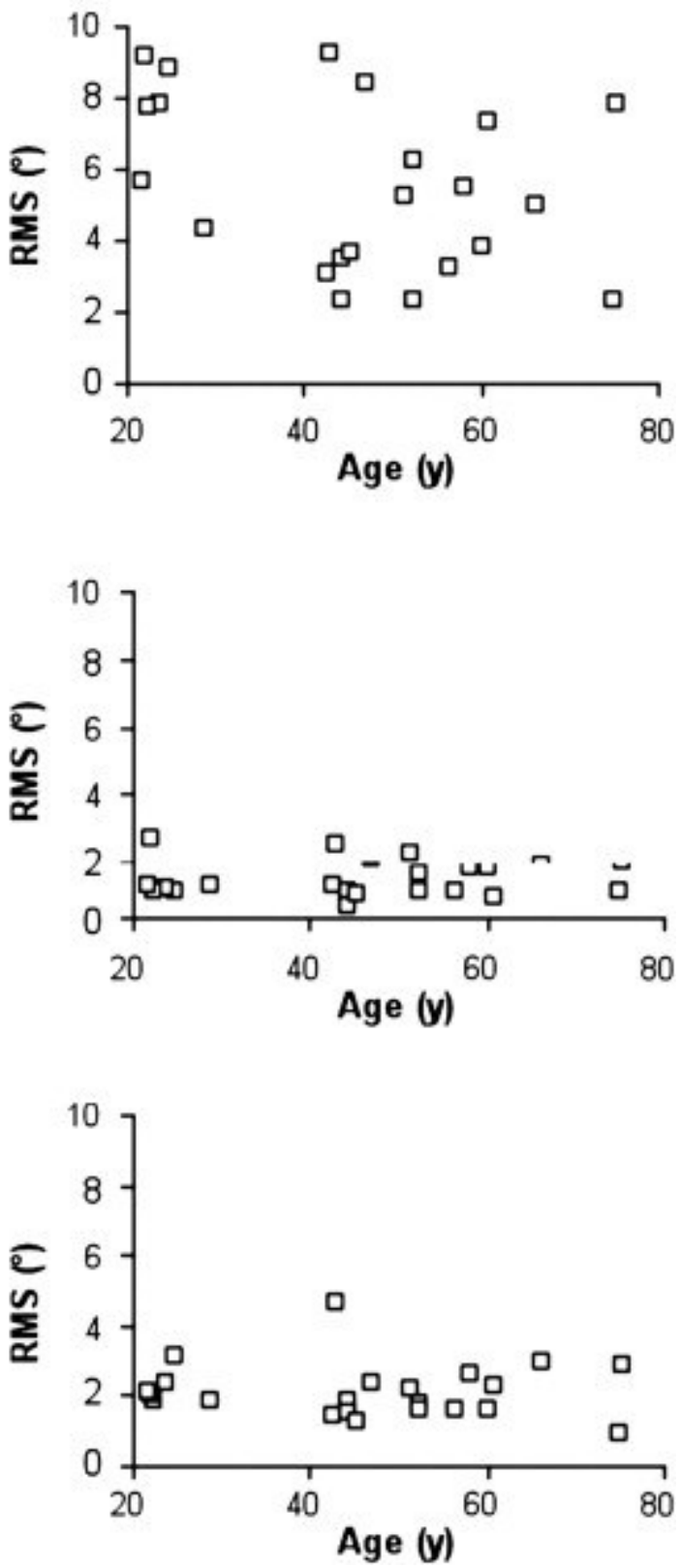

Fig. 1. Four variables found to have significant non-zero correlations with subject age: squat time, \%cycle at peak knee flexion, maximum ab/adduction, and minimum ab/adduction. 


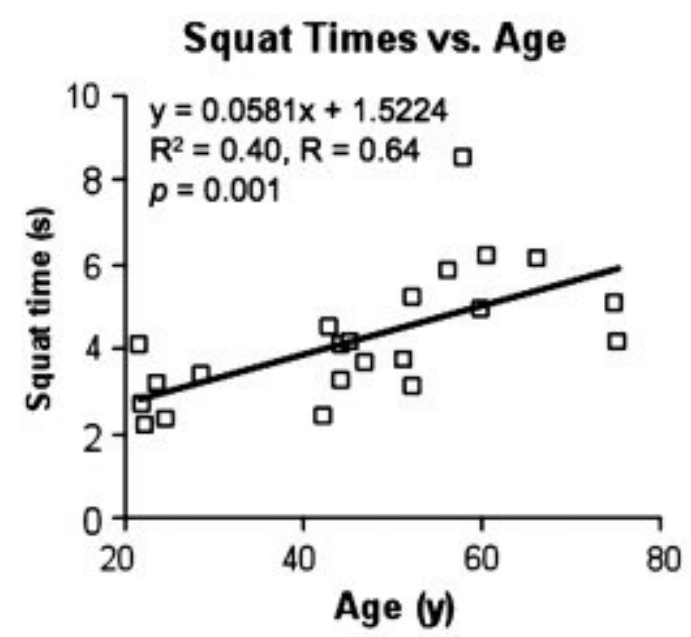

Max ab/adduction vs. Age

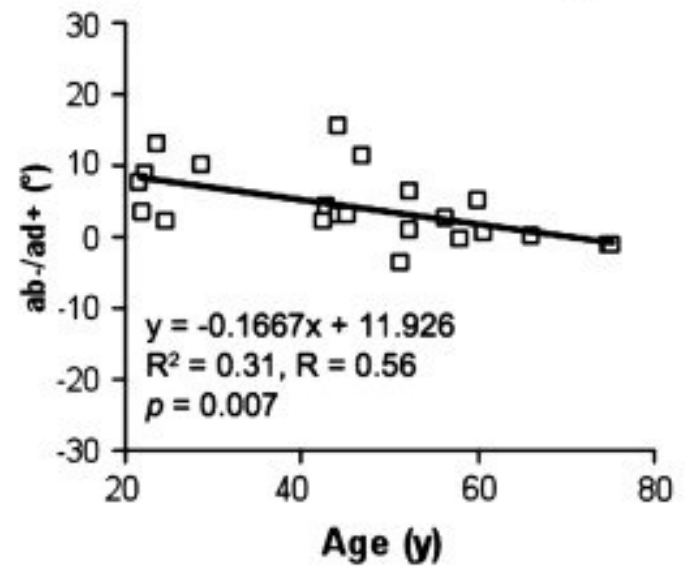

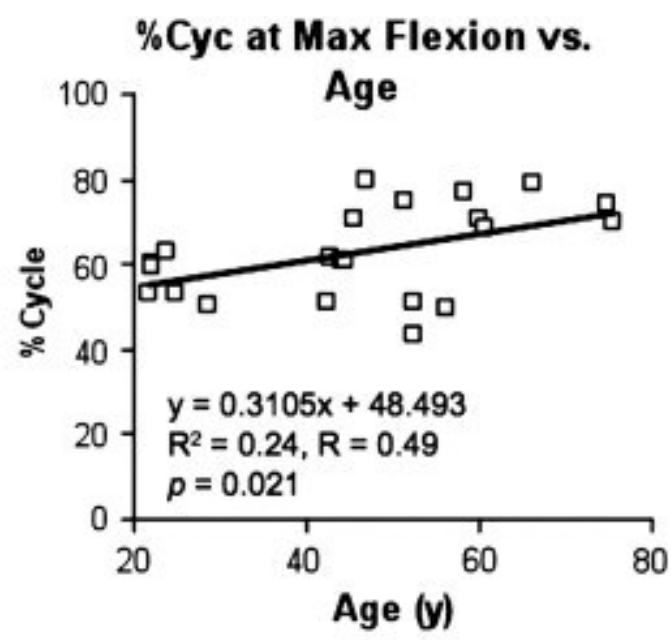

Min ab/adduction vs. Age

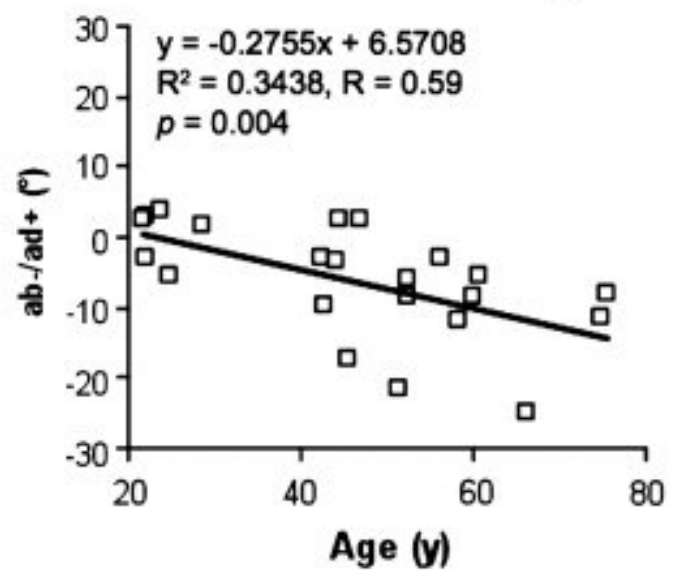

Fig. 2. Repeatability of the knee rotation curves versus subject age. Repeatability relative to the range of motion was measured by the coefficient of multiple correlation (CMC). Absolute repeatability, in degrees, was measured with the root-mean-square of the errors (RMS), which is similar to the average standard deviation of the curves across the entire cycle. Repeatability of knee rotations appeared unaffected by age. 
Table 2. Overview of parameters analyzed.

\begin{tabular}{|c|c|c|c|}
\hline Category & Parameter & $\begin{array}{c}\text { Correlation with } \\
\text { age }\end{array}$ & $p$ \\
\hline & Age & $\mathrm{n} / \mathrm{a}$ & \\
\hline \multirow{5}{*}{$\begin{array}{l}\text { Subject } \\
\text { parameters }\end{array}$} & Body mass (kg) & 0.156 & 0.489 \\
\hline & Height $(\mathrm{cm})$ & -0.270 & 0.225 \\
\hline & Body-mass index & 0.353 & 0.107 \\
\hline & CMC, knee flexion-extension & 0.265 & 0.234 \\
\hline & CMC, knee abduction-adduction & 0.059 & 0.801 \\
\hline \multirow{11}{*}{ Repeatability } & $\mathrm{CMC}$, knee in-external rotation & -0.068 & 0.764 \\
\hline & RMS $\left(^{\circ}\right)$, knee flexion-extension & -0.371 & 0.089 \\
\hline & RMS $\left(^{\circ}\right)$, knee abduction-adduction & 0.051 & 0.821 \\
\hline & RMS $\left(^{\circ}\right)$, knee in-external rotation & -0.093 & 0.681 \\
\hline & Hip abduction-adduction at start $\left(^{\circ}\right)$ & -0.098 & 0.665 \\
\hline & Hip in-external rotation at start $\left(^{\circ}\right)$ & -0.095 & 0.674 \\
\hline & Ankle abduction-adduction at start $\left(^{\circ}\right)$ & 0.234 & 0.294 \\
\hline & Ankle in-external rotation at start $\left(^{\circ}\right)$ & -0.222 & 0.321 \\
\hline & Knee flexion-extension at start $\left(^{\circ}\right)$ & 0.389 & 0.073 \\
\hline & Knee flexion-extension maximum $\left(^{\circ}\right)$ & -0.245 & 0.273 \\
\hline & Knee flexion-extension excursion $\left(^{\circ}\right)$ & -0.347 & 0.114 \\
\hline \multirow{7}{*}{ Kinematics } & $\begin{array}{l}\text { Knee abduction-adduction at start } \\
\left({ }^{\circ}\right)\end{array}$ & -0.436 & 0.042 \\
\hline & $\begin{array}{l}\text { Knee abduction-adduction } \\
\text { maximum }\left({ }^{\circ}\right)\end{array}$ & -0.559 & 0.007 \\
\hline & $\begin{array}{l}\text { Knee abduction-adduction minimum } \\
\left(^{\circ}\right)\end{array}$ & -0.586 & 0.004 \\
\hline & $\begin{array}{l}\text { Knee abduction-adduction excursion } \\
\left(^{\circ}\right)\end{array}$ & 0.355 & 0.105 \\
\hline & Knee in-external rotation maximum $\left(^{\circ}\right)$ & -0.263 & 0.237 \\
\hline & Knee in-external rotation minimum $\left(^{\circ}\right)$ & 0.040 & 0.861 \\
\hline & Knee in-external rotation excursion $\left(^{\circ}\right)$ & -0.359 & 0.100 \\
\hline \multirow{2}{*}{ Timing } & Cycle time (s) & 0.636 & 0.001 \\
\hline & $\%$ Cycle at deepest flexion (\%) & 0.488 & 0.021 \\
\hline
\end{tabular}

Summary of parameters analyzed. Parameters found to have significant correlations with age are highlighted.

Further analysis revealed that the lack of significance of some parameters was mainly due to outlier data from one 21.9 year-old female subject. The subject took on a relatively wide squatting stance, with $15.7^{\circ}$ starting hip abduction versus a subject average of $8.4^{\circ}$. This led to apparent squat difficulty and reduced range of knee flexion. When the data from this subject 
were eliminated, additional significant correlations were detected between age and maximal flexion, and internal-external rotation of the knee joint. However, only the full set of original data is reported here, since only some of the data from this subject were outliers, and the subject was free to choose her own stance.

When the subjects were grouped in two age groups, there was no statistically significant difference between "younger" ( $<45$ years) and "older" ( $>45$ years) groups. However, a trend was observed that older subjects showed more thorax anterior tilt, more hip flexion, smaller and delayed maximal knee flexion, more knee abduction, less knee internal rotation, and less ankle dorsiflexion. Generally these patterns indicated more anterior leaning by older subjects.

\section{Discussion}

The aim of this study was to investigate the kinematics of a deep knee squat activity in healthy subjects with a wide variability in age, and to document the influence of age on how a deep knee squat is performed. This study confirmed that some aspects of the squat kinematics vary significantly with age, and that the basic methodology employed in our study can successfully detect these age-related trends.

The main finding in this study was that increased age was correlated with larger maximal knee abduction during the squat. To our knowledge, age-related difference in abductionadduction kinematics during squat has not been evaluated before. The current study revealed that older subject had more valgus alignment during a squat maneuver. Abd-adduction alignment during movement can cause an imbalanced articular load distribution, and potential articular surface separation after TKA. Several authors have reported about articular surface separation, or 'lift-off' after TKA [27], [28] and [29], but age-related kinematic changes were never taken into account in its interpretation. The results of this study therefore suggest that age-matched kinematic analysis including the coronal plane would be needed in future clinical studies.

Many authors have reported on the influence of aging on normal gait [18] and [19], which is attributed by the fact that aging-related neuromuscular impairment is associated with a significant decline in muscle strength, secondary to a loss of muscle mass. This study demonstrated that older subjects needed longer time for performing a squat, especially in descending phase. Group comparison between ages showed a trend that older subjects also 
showed more anterior inclination of the thorax and pelvis, more flexion in the hip joint, less flexion in the knee and ankle joint. Just as what has been demonstrated for gait, age-related muscular weakness may provide an explanation for these results.

With respect to the transverse plane, our data demonstrated that tibia rotated internally with increasing flexion during squat. This is in agreement with previous reports [11], [12], [30] and [31], but interesting to note was that older group showed a trend towards less internal rotation compared to younger subjects. This means that older subjects probably demonstrate less "roll back" movement of the lateral condyle. Multiple factors have an influence on femoral roll back, such as the status of the cruciate ligaments, collateral ligaments, and menisci. Several authors have reported age-related changes of these structures [32], which could be a possible explanation for our findings.

Despite the fact that we believe that the findings from our study are interesting and shed new light on the normal kinematics during a knee squat, our work has also some limitations. The sample size is relatively small leading to unequal gender distributions. Numerous studies have demonstrated that women have different motion patterns than men [33], [34], [35] and [36]. Further study with more subjects distinguishing female to male would therefore be needed. Some trends between older and younger subjects in group comparisons were seen, but not statistically significant in this study. Desloovere et al. reported that squat kinematics has only smaller repeatability than other activities such as normal walking or turning, because of the smaller constraints of the knee joint [37]. There is a possibility to detect some findings when larger number of the subjects was studied. Another limitation of this study is that stance widths while squatting were not uniform. The stance width would have an influence on the kinematics of all the joints. The results might have been different with a constant stance. However, we evaluated the natural way of the squatting activity like these subjects would have done in their daily lives.

\section{Conclusion}

In conclusion, our study has demonstrated that some aspects of squat kinematics vary significantly with age. We therefore believe that age-matched control data are required whenever the performance of an implant or surgical procedure is evaluated during a deep knee squat. 


\section{Conflict of interest}

This study was sponsored by and conducted at the European Centre for Knee Research, a part of Smith \& Nephew, Inc., which employs the authors and researcher P Wong and L Labey. The authors thank the staff and resources at Smith \& Nephew.

\section{References}

[1] J.N. Argenson, R.D. Komistek, J.M. Aubaniac, D.A. Dennis, E.J. Northcut, D.T. Anderson et al. In vivo determination of knee kinematics for subjects implanted with a unicompartmental arthroplasty J Arthroplasty, 17 (2002), pp. 1049-1054

[2] J. Bellemans, S. Banks, J. Victor, H. Vandenneucker, A. Moemans Fluoroscopic analysis of the kinematics of deep flexion in total knee arthroplasty. Influence of posterior condylar offset J Bone Joint Surg Br, 84 (2002), pp. 50-53

[3] H. Nozaki, S.A. Banks, T. Suguro, W.A. Hodge Observations of femoral rollback in cruciate-retaining knee arthroplasty Clin Orthop Relat Res, 404 (2002), pp. 308-314

[4] S.A. Banks, J. Bellemans, H. Nozaki, L.A. Whiteside, M. Harman, W.A. Hodge Knee motions during maximum flexion in fixed and mobile-bearing arthroplasties Clin Orthop Relat Res, 410 (2003), pp. 131-138

[5] S.A. Banks, W.A. Hodge Design and activity dependence of kinematics in fixed and mobile-bearing knee arthroplasties J Arthroplasty, 19 (2004), pp. 809-816

[6] S. Fantozzi, F. Catani, A. Ensini, A. Leardini, S. Giannini Femoral rollback of cruciateretaining and posterior-stabilized total knee replacements: in vivo fluoroscopic analysis during activities of daily living J Orthop Res, 24 (2006), pp. 2222-2229

[7] J. Victor, J. Bellemans Physiologic kinematics as a concept for better flexion in TKA Clin Orthop Relat Res, 452 (2006), pp. 53-58

[8] B.J. Schoenfeld Squatting kinematics and kinetics and their application to exercise performance J Strength Cond Res, 24 (2010), pp. 3497-3506

[9] S. Hwang, Y. Kim, Y. Kim Lower extremity joint kinetics and lumbar curvature during squat and stoop lifting BMC Musculoskelet Disord, 10 (2009), p. 15

[10] F.C. Kuo, W.P. Kao, H.I. Chen, C.Z. Hong Squat-to-reach task in older and young adults: kinematic and electromyographic analyses Gait Posture, 33 (2011), pp. 124-129

[11] R.D. Komistek, D.A. Dennis, M. Mahfouz In vivo fluoroscopic analysis of the normal human knee Clin Orthop Relat Res, 410 (2003), pp. 69-81

[12] T.A. Moro-oka, S. Hamai, H. Miura, T. Shimoto, H. Higaki, B.J. Fregly et al. Dynamic activity dependence of in vivo normal knee kinematics J Orthop Res, 26 (2008), pp. 428-434 
[13] S.J. Olney, M.P. Griffin, I.D. McBride Temporal, kinematic, and kinetic variables related to gait speed in subjects with hemiplegia: a regression approach Phys Ther, 74 (1994), pp. 872-885

[14] J.O. Judge, R.B. Davis III, S. Ounpuu Step length reductions in advanced age: the role of ankle and hip kinetics J Gerontol A Biol Sci Med Sci, 51 (1996), pp. M303-M312 [15] D.C. Kerrigan, L.W. Lee, J.J. Collins, P.O. Riley, L.A. Lipsitz Reduced hip extension during walking: healthy elderly and fallers versus young adults Arch Phys Med Rehabil, 82 (2001), pp. 26-30

[16] J.B. Dingwell, L.C. Marin Kinematic variability and local dynamic stability of upper body motions when walking at different speeds J Biomech, 39 (2006), pp. 444-452

[17] S. Ko, S.M. Ling, J. Winters, L. Ferrucci Age-related mechanical work expenditure during normal walking: The Baltimore Longitudinal Study of Aging J Biomech, 42 (2009), pp. 1834-1839

[18] S.R. Lord, D.G. Lloyd, S.K. Li Sensori-motor function, gait patterns and falls in community-dwelling women Age Ageing, 25 (1996), pp. 292-299

[19] A.F. Polcyn, L.A. Lipsitz, D.C. Kerrigan, J.J. Collins Age-related changes in the initiation of gait: degradation of central mechanisms for momentum generation Arch Phys Med Rehabil, 79 (1998), pp. 1582-1589

[20] I. Kanisawa, A.Z. Banks, S.A. Banks, H. Moriya, A. Tsuchiya Weight-bearing knee kinematics in subjects with two types of anterior cruciate ligament reconstructions Knee Surg Sports Traumatol Arthrosc, 11 (2003), pp. 16-22

[21] D.A. Dennis, M.R. Mahfouz, R.D. Komistek, W. Hoff In vivo determination of normal and anterior cruciate ligament-deficient knee kinematics J Biomech, 38 (2005), pp. 241-253 [22] L.E. Defrate, R. Papannagari, T.J. Gill, J.M. Moses, N.P. Pathare, G. Li The 6 degrees of freedom kinematics of the knee after anterior cruciate ligament deficiency: an in vivo imaging analysis Am J Sports Med, 34 (2006), pp. 1240-1246

[23] S. Hamai, T.A. Moro-oka, H. Miura, T. Shimoto, H. Higaki, B.J. Fregly et al. Knee kinematics in medial osteoarthritis during in vivo weight-bearing activities J Orthop Res, 27 (2009), pp. 1555-1561

[24] M.P. Kadaba, H.K. Ramakrishnan, M.E. Wootten, J. Gainey, G. Gorton, G.V. Cochran Repeatability of kinematic, kinetic, and electromyographic data in normal adult gait J Orthop Res, 7 (1989), pp. 849-860 
[25] A.G. Schache, R. Baker, L.W. Lamoreux Defining the knee joint flexion-extension axis for purposes of quantitative gait analysis: an evaluation of methods Gait Posture, 24 (2006), pp. 100-109

[26] J.L. McGinley, R. Baker, R. Wolfe, M.E. Morris The reliability of three-dimensional kinematic gait measurements: a systematic review Gait Posture, 29 (2009), pp. 360-369

[27] D.A. Dennis, R.D. Komistek, S.A. Walker, E.J. Cheal, J.B. Stiehl Femoral condylar liftoff in vivo in total knee arthroplasty J Bone Joint Surg Br, 83 (2001), pp. 33-39

[28] G.R. Scuderi, R.D. Komistek, D.A. Dennis, J.N. Insall The impact of femoral component rotational alignment on condylar lift-off Clin Orthop Relat Res, 410 (2003), pp. 148-154

[29] J.B. Stiehl, D.A. Dennis, R.D. Komistek, H.S. Crane In vivo determination of condylar lift-off and screw-home in a mobile-bearing total knee arthroplasty J Arthroplasty, 14 (1999), pp. 293-299

[30] T. Asano, M. Akagi, K. Tanaka, J. Tamura, T. Nakamura In vivo three-dimensional knee kinematics using a biplanar image-matching technique Clin Orthop Relat Res, 388 (2001), pp. $157-166$

[31] P. Johal, A. Williams, P. Wragg, D. Hunt, W. Gedroyc Tibio-femoral movement in the living knee. A study of weight bearing and non-weight bearing knee kinematics using 'interventional' MRI J Biomech, 38 (2005), pp. 269-276

[32] C.C. Carroll, J.M. Dickinson, J.M. Haus, G.A. Lee, C.J. Hollon, P. Aagaard et al. Influence of aging on the in vivo properties of human patellar tendon J Appl Physiol, 105 (2008), pp. 1907-1915

[33] R.A. Malinzak, S.M. Colby, D.T. Kirkendall, B. Yu, W.E. Garrett A comparison of knee joint motion patterns between men and women in selected athletic tasks Clin Biomech (Bristol, Avon), 16 (2001), pp. 438-445

[34] J.D. Chappell, B. Yu, D.T. Kirkendall, W.E. Garrett A comparison of knee kinetics between male and female recreational athletes in stop-jump tasks Am J Sports Med, 30 (2002), pp. 261-267

[35] M.J. Decker, M.R. Torry, D.J. Wyland, W.I. Sterett, J. Richard Steadman Gender differences in lower extremity kinematics, kinetics and energy absorption during landing Clin Biomech (Bristol, Avon), 18 (2003), pp. 662-669

[36] J.H. Hollman, R.H. Deusinger, L.R. Van Dillen, M.J. Matava Gender differences in surface rolling and gliding kinematics of the knee Clin Orthop Relat Res, 413 (2003), pp. $208-221$

[37] K. Desloovere, P. Wong, L. Swings, B. Callewaert, H. Vandenneucker, A. Leardini 
Range of motion and repeatability of knee kinematics for 11 clinically relevant motor tasks Gait Posture, 32 (2010), pp. 597-602

Corresponding author. Department of Orthopaedics, University Hospitals Leuven (campus Pellenberg), Katholieke Universiteit Leuven, Weligerveld 1, 3212 Pellenberg, Belgium. Tel.: + 3216338800 (office). 